\title{
A reforma pombalina e suas implicações para a educação brasileira em meados do século XVIII
}

The Pombaline reform and its implications for Brazilian education in the mid-18th century

Alexandre Shigunov Neto (iD)

e-mail: shigunov.ifsp.edu@gmail.com Instituto Federal de Educação, Ciência e Tecnologia de São Paulo - IFSP campus Itapetininga/Brasil

Dulce Maria Strieder (iD)

e-mail: dulce.strieder@unioeste.br Universidade Estadual do Oeste do Parana. Parana/Brasil

André Coelho da Silva (iD) e-mail: andco_8@yahoo.com.br

Instituto Federal de Educação, Ciência e Tecnologia de São Paulo - IFSP campus Itapetininga/Brasil

\section{Resumo}

O conhecimento histórico da educação formal brasileira é basilar para a compreensão do contexto educacional de mudança vivido na atualidade e o estabelecimento de encaminhamentos analíticos diferenciados. Neste sentido, e a partir da premissa de que as ideologias próprias de cada momento histórico direcionam a implantação de propostas educacionais, a presente pesquisa pretendeu analisar a importância de se compreender tanto o importante período da historiografia da educação brasileira como o impacto das reformas educacionais efetuadas no Brasil Colônia por Sebastião José de Carvalho e Melo, o Marquês de Pombal. O período analisado foi denominado como a fase governativa (1750-1777), ocorrida durante o reinado de Dom José I em Portugal e que culminou com as Reformas Pombalinas implementadas em Portugal e no Brasil Colônia. Tais reformas, de caráter antijesuítico, centraram-se em medidas, cujos objetivos eram desmantelar o sistema educacional vigente e atribuir a esse a decadência educacional do império daquele momento histórico a fim de alavancar Portugal a partir de uma nova orientação 'cultural' e pela superexploração colonial. A pesquisa, qualitativa e de cunho bibliográfico, denota que a reforma pombalina desestabilizou uma organização educacional já consolidada sem implementar um novo modelo em substituição, o qual significou um retrocesso no desenvolvimento educacional, especialmente no contexto brasileiro ainda em estruturação.

Palavras-chave: Brasil colônia; reformas educacionais; Historiografia da educação; Marquês de Pombal.

\begin{abstract}
The historical knowledge of Brazilian formal education is primordial to perceive the educational context of change, which has been lived nowadays and the establishment of differentiated analytical referrals. Thus, based on the premise that the ideologies of each historical moment have directed the implementation of educational proposals, this research aimed at analyzing the importance of understanding both the important historiographic period of Brazilian education and the impact of the educational reforms that have been carried out in Brazil Colony by Sebastião José de Carvalho e Melo, the Marquis of Pombal. The studied period was named as the governmental phase (1750-1777), which occurred during the reign of Dom José I in Portugal and ended in the Pombaline Reforms implemented in Portugal and in Brazil Colony. Such anti-Jesuitical reforms focused on measures whose goals were to take apart the current educational system and to attribute to it the educational decadence of the empire regarding that historical moment in order to put Portugal forward from a new 'cultural' guidance and colonial overexploitation. This is a qualitative and bibliographical research, which shows that the Pombaline reform has destabilized an already safe educational organization without settling down a new model instead. And this meant a backset in educational development, especially in the Brazilian context still under organization.
\end{abstract}

Keywords: Brazil Colony; educational reforms; Historiography of education; Marquis of Pombal.

Recibido / Received: 30-05-2018

Aceptado / Accepted: 04-10-2018

Cómo referenciar este artículo / How to reference this article:

Shigunov Neto, A., Strieder, D.M., \& Silva, A.C. da. (2019). A reforma pombalina e suas implicações para a educação brasileira em meados do século XVIII. Tendencias Pedagógicas, 33, 117-126. doi: 10.15366/tp2019.33.009 


\section{Introdução}

O objetivo deste texto é realizar uma análise das reformas educacionais efetuadas no Brasil colônia por Sebastião José de Carvalho e Melo, o Marquês de Pombal. Neste sentido, para assentar o locus e o momento histórico analisado, é imperioso tratar dos diferentes períodos da educação nacional.

Saviani (2013) em seu estudo das ideias pedagógicas propõe uma periodização das ideias pedagógicas no Brasil, partindo de uma classificação das principais concepções de educação. Essa classificação apresenta quatro grandes períodos, assim divididos:

$1^{\circ}$ período (1549-1759) - monopólio da vertente religiosa da pedagogia tradicional, subdividida nas seguintes fases:

1) uma pedagogia brasílica ou o período heroico (1549-1599)

2) a institucionalização da pedagogia jesuítica ou o Ratio Studiorum (1559-1759)

$2^{\circ}$ período (1759-1932) - Coexistência entre as vertentes religiosa e leiga da pedagogia tradicional, subdividida nas seguintes fases:

1) A pedagogia pombalina ou as ideias pedagógicas do despotismo esclarecido (1759-1827)

2) Desenvolvimento da pedagogia leiga: ecletismo, liberalismo e positivismo (1827-1932)

$3^{\circ}$ período (1932-1969) - Predominância da pedagogia nova, subdividido nas seguintes fases:

1) Equilíbrio entre a pedagogia tradicional e a pedagogia nova (1932-1947)

2) Predomínio da influência da pedagogia nova (1947-1961)

3) Crise da pedagogia nova e articulação da pedagogia tecnicista (1961-1969)

$4^{\circ}$ período (1969-2001) - Configuração da concepção pedagógica produtivista, subdividido nas seguintes fases:

1) Predomínio da pedagogia tecnicista, manifestações da concepção analítica de filosofia da educação e concomitante desenvolvimento da visão crítico-reprodutivista (1969-1980)

2) Ensaios contra-hegemônicos: pedagogia da "educação popular", pedagogia da prática, pedagogia crítico-social dos conteúdos e pedagogia histórico-crítica (1980-1991)

A análise ora implementada, situa-se no $2^{\circ}$ período, entretanto, a compreensão de suas origens perpassa o $1^{\circ}$ período, assim como os resultados abrangem os períodos posteriores. Tal análise também não se propõe a ser única, sendo que entre os pesquisadores que discutem a temática do ensino brasileiro no período pombalino, destacam-se: Teixeira Soares (1961), Haidar (1973), Azevedo (1976), Carvalho (1978), Rêgo (1982), Santos (1982), Serrão (1982), Avellar (1983), Cunha (1986), Falcon (1993), Holanda (1993), Romanelli (1993), Ribeiro (1998) e Almeida (2000), Ghiraldelli Jr. (2009), Maciel \& Shigunov Neto (2006), Saviani (2013) e Shigunov Neto (2015).

Sebastião José de Carvalho e Melo, conde de Oeiras, mais conhecido como Marquês de Pombal, nasceu em 13 de maio de 1699. Pertencia a uma família da pequena nobreza, esteve no exército e foi membro da Academia Real de História. Sua vida pública somente teve início a partir de 1738, quando foi nomeado para desempenhar as funções de delegado de negócios em Londres.

Para Falcon (1993), a análise da obra e da vida do Marquês de Pombal pode ser dividida em seis períodos. O primeiro é composto por análises realizadas por historiadores/pesquisadores contemporâneos de Sebastião. O segundo se estrutura a partir de admiradores e críticos imediatos de suas obras. O terceiro é composto por análises de liberais que gestaram o mito do liberalismo pombalino. O quarto é estruturado por conservadores que fundam o mito da tirania pombalina. $\mathrm{O}$ quinto se refere aos estudos apresentados por pesquisadores/historiadores durante a primeira metade do século XX. E o sexto engloba as análises mais recentes, iniciadas por volta de 1945. 
Podemos considerar que a vida pública de Sebastião José de Carvalho e Melo se iniciou em 1738 quando foi nomeado pelo governo português para desempenhar as funções de delegado de negócios em Londres. De fato, sua vida em termos de reconhecimento frente ao império pode ser dividida em quatro fases: a fase dos interesses particulares; a fase diplomática; a fase governativa; e a fase do exílio. $\mathrm{Na}$ primeira, que vai de 1699 a 1738 , ele se dedicou exclusivamente a seus interesses pessoais enquanto pequeno fidalgo. O marco final dessa fase é a tentativa frustrada do Marquês de Pombal em compor o Conselho de Fazenda do rei D. João V. A fase diplomática compreende o período de 1738 a 1749. Trata-se da época em que Sebastião exerceu funções diplomáticas em Londres e Viena. A terceira fase, a governativa, que vai de 1750 a 1777, pode ser considerada a mais importante de sua vida. Foi nesse período, durante o reinado de Dom José I em Portugal, que Sebastião teve papel fundamental na direção dos negócios do país. Por fim, a quarta fase de sua vida compreende o período em que ficou exilado: entre a morte de D. José I em 1777 e sua própria morte em 1782. (Shigunov Neto, 2015)

Para fins dessa pesquisa nos interessa analisar a terceira fase da vida do Marquês de Pombal, ao assumir o cargo de ministro da Fazenda do rei D. José I em 02 de agosto de 1750 no lugar de Azevedo Coutinho. Nesta fase, Pombal empreendeu reformas administrativas, visando aumentar a arrecadação de dinheiro e a agilidade/eficiência da máquina administrativa do Estado português. Ainda no campo das reformas administrativas e econômicas, pretendia com essas medidas dinamizar a economia nacional e incentivar o desenvolvimento das indústrias e das companhias de comércio, adaptando a sociedade portuguesa aos movimentos sociais, culturais, econômicos e políticos que estavam ocorrendo na Europa do século XVIII. Contudo, essa tentativa de consolidar um polo industrial forte e em condições de competir no mercado interno e externo acabou não prosperando. Muitas das novas indústrias que surgiram tiveram curto período de funcionamento em virtude da pequena demanda do mercado interno e do fato de que os produtos manufaturados ingleses possuíam melhor qualidade (Shigunov Neto, 2015).

O conjunto de reformas empreendidas pelo Marquês de Pombal nessa terceira fase foram denominadas de Reforma Pombalina. Além de reordenamentos econômicos e administrativos, ela implicou também em mudanças educacionais para Portugal e suas colônias. Especificamente no Brasil, a Reforma Pombalina atuou junto à reformulação dos serviços públicos e do combate à sonegação fiscal. Sua preocupação orientava-se no sentido de proporcionar um senso de unidade à colônia brasileira. No que diz respeito à organização educacional no Brasil, ela caiu como uma bomba, desmantelando o trabalho que vinha sendo desenvolvido há dois séculos pelos jesuítas.

Teixeira Soares (1961) elencou os principais problemas da administração do governo de D. João $\mathrm{V}$, que atingiam o Império e a colônia. Esses problemas foram combatidos posteriormente pelo Marquês de Pombal em sua fase governativa durante o governo de D. José I:

- o apego à rotina - evitando a realização de reformas necessárias e úteis ao funcionamento da estrutura administrativo do Estado, principalmente em relação ao regime fazendário e à administração ultramarina;

- o desinteresse pela instrução pública, que na Coroa portuguesa era um privilégio dos nobres e da burguesia;

- o obscurantismo existente em todos os níveis do Governo e que dificultava as reformas necessárias.

De acordo com Teixeira Soares (1961), Rêgo (1982), Serrão (1982) Santos (1982), Falcon (1993) e Ribeiro (1998), o Marquês de Pombal foi fortemente influenciado em sua formação política quando de sua passagem como diplomata em Viena (1745-1749). De fato, ele procurou soluções para a crise portuguesa se espelhando no modelo econômico britânico, não obtendo êxito, contudo, devido a existência de uma contradição fundamental: a diferença no sistema político dos dois países. Em Portugal estava instituído o absolutismo e na Inglaterra o parlamentarismo.

Ribeiro (1998) destaca que o Marquês de Pombal com o intuito e recuperar a economia portuguesa utiliza-se da concentração do poder real e da modernização da cultura. E que a fonte das 
transformações defendidas estava presente no movimento iluminista.

"É assim que não chega a representar uma ruptura total com a tradição. Isto pode ser constatado pelas obras dos filósofos inspiradores, como Luís Antônio Verney e Antônio Genovesi, onde é percebida uma mudança mais de conteúdo do que método. Este ainda se mantém bastante preso à exposição escolástica. Pode ser constatado, também, pelo fato de a Real Mesa Censória, criada e, 1768, ter proibido, durante seu período de exército, obras de Locke, Hobbes, Rousseau, Sinosa, Voltaire, etc. porque poderiam levar o país na direção do deísmo, ateísmo e materialismo". (Ribeiro, 1998, p.36)

Para alcançar seu principal objetivo, isto é, a transformação da nação portuguesa, o Marquês de Pombal precisaria, inicialmente, fortalecer o Estado e o poder do rei em relação a outros grupos sociais como a nobreza e o clero, que tradicionalmente limitavam o poder real. Assim, uma das medidas pombalinas foi a expulsão dos jesuítas de todo o Império português. O respaldo para essa decisão foi encontrado na preocupação da Coroa portuguesa com o enriquecimento da Companhia de Jesus, na sua influência política e na acusação de um possível interesse dos jesuítas em organizarem um "império teocrático" na região das missões. O espírito antijesuítico foi expresso, em última análise, na atribuição dos males e da decadência da educação e da cultura na Metrópole e na colônia brasileira à Companhia de Jesus. Acrescente-se ao discurso pombalino que a presença jesuítica nos domínios portugueses colocaria em risco os projetos reformadores a serem adotados, visto a influência que exerciam em todos os setores da sociedade (Shigunov Neto, 2015).

As proposta reformistas relativas ao Brasil visavam a reformulação dos serviços públicos, por meio, do combate a sonegação de impostos. Sua preocupação orientava-se no sentido de proporcionar uma unidade, um conjunto à colônia brasileira. Entretanto, o que em Portugal representou um projeto de reordenamento cultural, que deu as bases para a criação de um sistema público de ensino, no Brasil, o resultado foi o oposto, com a educação sendo afetada negativamente.

\begin{abstract}
"Depois desta análise do valor excepcional destas escolas, cumpre-nos explicar a extrema hostilidade suscitada por elas entre os protestantes e a oposição da Igreja Católica Romana, o que determinou a supressão temporária da Ordem. Em grande parte esta hostilidade foi devida às atividades políticas da Ordem, e estas atividades vinham da aplicação do princípio fundamental da Ordem de que tudo há de ser feito para a maior glória de Deus (...). Tratava-se de assegurar essa glória por meio do progresso dos interesses da Igreja. Na prática, o princípio significava a completa subordinação do indivíduo à Ordem, da Ordem, de todos os que ela educava ou sobre quem exercesse influência, à Igreja. Ainda uma vez, tanto em princípio quanto na prática, o indivíduo tinha de desaparecer completamente ante a instituição. O princípio francamente declarado pela Ordem em sua obra, e expresso nos voto dos membros, era a completa subordinação do indivíduo. Isso visava a seu plano educacional.

(...) A prática e o princípio da educação jesuíta estavam em oposição aos novos ideais do período do Renascimento. Seu método, perfeito à sua maneira, inibia toda iniciativa e impedia o desenvolvimento de toda espontaneidade e de toda liberdade de opinião. Sua superioridade durou enquanto não houve nenhuma grande modificação no espírito e conteúdo da educação. Mas, quando o século XVIII surgiu com um decidido movimento fora do espírito teológico dominante e do conteúdo humanista formal de educação, as escolas jesuítas perderam muito do seu prestígio e superioridade”. (Monroe,1978,p.186-187)
\end{abstract}

Assim sendo, a proclamada reforma econômica portuguesa, mas que efetivamente apresentava um caráter administrativo-fiscal, teve no Brasil o efeito de uma bomba, com os seus estilhaços desmantelando o trabalho educacional de dois séculos dos jesuítas, o que exigia uma nova orientação.

O que em Portugal representou um projeto de reordenamento cultural, configurando as bases para a criação de um sistema público de ensino, no Brasil representou o desmantelamento do projeto educacional que vinha sendo desenvolvido até então.

\title{
Segundo Monroe (1978):
}

“[...] A prática e o princípio da educação jesuíta estavam em oposição aos novos ideais do período do Renascimento. Seu método, perfeito à sua maneira, inibia toda iniciativa e impedia o desenvolvimento de toda espontaneidade e de toda liberdade de opinião. Sua superioridade durou enquanto não houve nenhuma grande modificação no espírito e conteúdo da educação. Mas, quando o século XVIII surgiu 
com um decidido movimento fora do espírito teológico dominante e do conteúdo humanista formal de educação, as escolas jesuítas perderam muito do seu prestígio e superioridade”. (p.186-187)

A renovação pedagógica pretendida pelo Marquês de Pombal, não foi originalidade e exclusividade de seu governo, pois em outros governos, como os de D. João V e de D. Maria I, que, respectivamente, antecederam e sucederam o governo de D. João I (em que Sebastião participou), encontram-se os traços dessa influência iluminista. Logo, há que se frisar que as transformações na sociedade portuguesa efetuadas sob o comando do Marquês de Pombal estavam respaldadas pelos ideais iluministas em Portugal, os quais, devido às influências da igreja católica apresentavam algumas peculiaridades que o diferenciam do modelo encontrado em outras nações europeias como França, Inglaterra e Alemanha (Serrão, 1982; Carvalho, 1978; Holanda 1993; Ribeiro, 1998; Saviani, 2013).

O homem necessário à nova sociedade em formação seria alcançado por intermédio da educação, por conseguinte, a metodologia jesuítica já não estava em consonância com os interesses dos Estados Modernos em formação, ou seja, surge a ideia de educação pública sob o controle dos Estados Modernos.

"O século XVIII foi chamado, pelos seus contemporâneos, de "século das luzes", em oposição à "era das trevas", à Idade Média. O Iluminismo, como veio a ser conhecido o movimento intelectual do século, consistia na celebração da razão em oposição a qualquer religião revelada, consistente com a fé na ordem racional do mundo, a exaltação da ciência experimental e da técnica. Era a continuação, pela física de Newton, da mecânica de Galileu. O Iluminismo completava o Renascimento e criava espaço (ideológico) para o surgimento de doutrinas democráticas.

O Iluminismo foi, no final das contas, uma amplo e diferente movimento ideológico que, na direção das transformações iniciadas pela Reforma Protestante, organizava a luta da burguesia contra a aristocracia feudal e preparava sua hegemonia sobre toda a sociedade.

O Iluminismo português, obra dos "estrangeirados", não acompanhou a ilustração francesa e inglesa em todos os seus aspectos. Em Portugal, ao contrário dos outros países, o Iluminismo se compôs com a religião católica e a Igreja”. (Cunha,1986,p.44-45)

Para Saviani (2013) a reforma pombalina:

\begin{abstract}
"Defendia o desenvolvimento cultural do Império português pela difusão das novas ideias de base empirista e utilitaristas; pelo "derramamento das luzes da razão" nos mais variados setores da vida portuguesa; mas voltaram-se especialmente para a educação que precisaria ser libertada do monopólio jesuítico, cujo ensino se mantinha, conforme entendiam, preso a Aristóteles e avesso aos métodos modernos de fazer ciência" (p. 80).
\end{abstract}

Em Portugal, as medidas pombalinas como a expulsão da Companhia de Jesus de seus domínios, criaram condições para vicejar um Iluminismo contido, com um verniz científico (pois manteve a sua relação com a erudição literária, a imitação e a memorização). Acabaram também por incrementar o sistema de ensino, tanto o elementar quanto o médio, modalidade esta que possibilitou a formação de uma burocracia administrativa moderna e eficiente para atender às necessidades postas pelos novos tempos (Shigunov Neto, 2015).

\title{
1.1. As reformas educacionais do Marquês de Pombal
}

A partir do século XVI, a direção do ensino público português foi deslocada da Universidade de Coimbra para a Companhia de Jesus, que se responsabilizou pelo controle do ensino público em Portugal e, posteriormente, no Brasil. Foram, praticamente, dois séculos de domínio do método educacional jesuítico, até que no final do século XVIII, com a Reforma de Pombal, o ensino passou a ser responsabilidade da Coroa Portuguesa (Maciel \& Shigunov Neto, 2006).

Carvalho (1978) chama a atenção para o fato de que esse processo, denominado de antijesuitisimo representava uma atitude presente em muitos países europeus, não sendo exclusividade de Portugal. Nesse sentido, os jesuítas representavam um obstáculo e fonte de resistência às tentativas de implantação da nova filosofia iluminista que se difundia rapidamente por 
toda a Europa.

Conforme explicam Serrão (1992) e Almeida (2000), a ojeriza do Marquês de Pombal pelos jesuítas ficou expresso em documentos oficiais da época. Carvalho (1978) aponta que:

“[...] o tão celebrado ódio do Marquês de pombal à Companhia de Jesus não decorreu dos prejuízos opiniáticos de uma posição sistemática previamente traçada. Fatores vários e complexos, de ordem social, política e ideológica, influíram decisivamente na evolução de uma questão que ainda hoje apaixona e obnubila a visão dos espíritos mais esclarecidos. $\mathrm{Na}$ brevidade desta forma de ideal político nacional - a conservação da união cristã e da sociedade civil - se condensa toda uma filosofia com objetivos claramente definidos, responsável, aliás, de certa forma, tanto pelas virtudes quanto pelos vícios do despotismo imperante". (p. 32)

Portanto, tal espírito antijesuítico é expresso em última análise na atribuição à Companhia de Jesus de todos os males da educação na Metrópole e na colônia brasileira, bem como, pela decadência cultural e educacional imperante na sociedade portuguesa.

Por meio do Alvará de 28 de junho de 1759, o Ministro Marquês de Pombal tomou medidas no sentido de desmontar a organização educacional jesuítica, tanto no Brasil, quanto em Portugal. De acordo com Saviani (2013), embora o processo de implantação das reformas pombalinas tenha tido início no Brasil logo após a aprovação do Alvará de 1759, ela foi sendo implementada aos poucos, especialmente porque a Reforma de Pombal teve caráter predominantemente qualitativo.

Shigunov Neto (2015) destaca as principais medidas implantadas por intermédio do Alvará de 28 de junho de 1759 e que geraram a destruição da organização da educação jesuítica e sua metodologia de ensino, tanto no Brasil, quanto em Portugal:

- a instituição de aulas de gramática latina, de grego e de retórica;

- a criação do cargo de "diretor de estudos" - pretendia-se que fosse um órgão administrativo de orientação e fiscalização do ensino;

- a introdução das aulas régias - aulas isoladas que substituíram o curso secundário de humanidades criado pelos jesuítas;

- a realização de concurso para escolher professores para ministrar as aulas régias;

- a instituição de aulas de comércio.

Inspirado nos ideais iluministas, o Marquês de Pombal substituiu, ao menos formalmente, a metodologia eclesiástica dos jesuítas pelo pensamento pedagógico da escola pública e laica.

Segundo Santos (1982), o Marquês de Pombal, ao formular suas reformas educacionais - por intermédio da aprovação de decretos que criariam várias escolas e da reforma das já existentes -, estava preocupado, principalmente, em utilizar-se da instrução pública como instrumento ideológico e portanto, com o intuito de dominar a ignorância incompatível com o apoio a reformas esclarecidas. Em outras palavras: ao expulsar os jesuítas e, oficialmente, assumir a responsabilidade pela instrução pública, não se pretendia apenas reformar o sistema e os métodos educacionais, mas também colocá-lo ao serviço dos interesses políticos do Estado.

Almeida (2000) e Ribeiro (1998) concordam que o grande empecilho à efetivação das medidas foi a falta de pessoas capacitados para o ensino elementar e primário. Ou seja, havia, tanto na Metrópole, quanto na colônia, uma grande carência de professores aptos ao exercício da função de ensinar.

O Alvará de 28 de junho de 1759, por sua vez, transferiu a administração e a direção do ensino para a Real Mesa Censória, órgão criado em abril de 1768. Após esse ato, foram criadas no Brasil dezessete escolas de ler e escrever e instituído um fundo financeiro para a manutenção dos estudos reformados, denominado de subsídio literário. Uma das implicações do desmantelamento da organização educacional jesuítica e a falta de implantação de um projeto educacional formal e eficaz, 
fez com que apenas em 1776 se instituisse no Brasil colônia as escolas com cursos graduados e sistematizados (Shigunov Neto, 2015).

A esse respeito, Haidar (1973, p. 37) aponta que “[...] ao destruir a obra pedagógica dos jesuítas e, oficialmente, assumir a responsabilidade pela instrução pública, Pombal pretendera não apenas renovar o ensino em seus métodos e processos, mas laicizá-lo em seus objetivos, colocando-o a serviço dos interesses civis e políticos do Império Luso".

Para Cunha (1986):

"É enganoso supor que o Estado tivesse, antes de 1759, um plano de reforma educacional que orientasse todas as medidas que vieram a ser tomadas por Pombal nesse campo. Se é possível perceber a emergência de um programa cultural iluminista, desde a primeira metade do século XVIII, esse programa só ganhou sentido social e político, no período pombalino, através das contingências políticas". (p. 49).

Com um ensino preparatório, voltado para as humanidades, visava-se quer no Brasil, quer em Portugal, simplificar e modernizar a educação para atender às atividades requisitadas pelo dia a dia. Por outro lado, o elenco de vantagens apontadas pelo ensino reformulado, tais como: o ensino de línguas modernas, a exemplo o francês, assim como o desenho, a aritmética, a geometria e as ciências naturais, esbarraram-se na dispersão dos Colégios, na falta de formação dos professores e nas sucessivas queixas quanto a competência dos professores leigos. Acrescente-se a isso o fato de o centro das decisões estar localizado na Metrópole, o que refletia na morosidade da concretização das decisões (Shigunov Neto, 2015). Os limites impostos ao exercício administrativo se refletiu no Brasil, redundando num descuido na preparação do homem da colônia para uma carreira acadêmica na Europa.

$\mathrm{Na}$ tentativa de resolver o problema instalado, medidas paliativas foram adotadas. As chamadas Aulas Régias, por exemplo, conforme mencionado anteriormente, foram mantidas por um novo imposto, o "subsídio literário" - curiosamente criado treze anos após o decreto que as instituíram.

Com essas aulas, as autoridades portuguesas pretendiam ocupar os espaços deixados pelas disciplinas oferecias nos antigos colégios jesuíticos. Dessa forma, a população colonial, mesmo que de forma limitada, continuaria recebendo preparação para os estudos complementares na Europa.

Apesar das medidas antijesuíticas da proposta pombalina, encontram-se nela traços do ensino tradicional - eclesiástico, visto que muitos dos professores atuantes eram formados pela Companhia de Jesus e evidenciavam no exercício da sua atividade a influência da sua formação, embora em nível inferior ao dos religiosos. Portanto, não houve uma ruptura total com o ensino jesuítico.

A reformulação da Universidade de Coimbra, que era referencial para os jovens brasileiros que complementavam os seus estudos na Metrópole, também ocorreu no escopo da reforma pombalina. Em Coimbra, os brasileiros entravam em contato com as ideias de Locke, Rosseau e Voltaire, passando a aspirar e a fomentar a independência da colônia quando retornavam. De acordo com Cunha (1986):

“A reforma da Universidade de Coimbra, de 1770, é a mais conhecida medida de reforma educacional de Pombal. Às suas quatro faculdades maiores, Teologia, Cânones, Direito e Medicina, foram acrescentadas as de Matemática e de Filosofia, destinada esta ao ensino das ciências naturais. O conhecimento da natureza, baseado na observação, em vez de deduzido do pensamento dos sábios antigos, transformou-se na principal atividade não só da Faculdade de Filosofia, mas também das de Direito e de Medicina". (p. 53).

No ensino médio e, particularmente no ensino superior, sem perder de vista o academicismo ainda vigente, a adoção de novos conteúdos contribuiu para ampliar as possibilidades de formação do novo homem que deveria atender às necessidades do Império Português. No entanto, não há 
dúvidas de que todo esse movimento visava principalmente a recuperação econômica, que sustentava a tradição parasitária dos setores dominantes portugueses.

Tanto em Portugal quanto no Brasil, novas ordens religiosas assumiram a orientação espiritual da população, e por extensão, do processo educacional. Como exemplo, podemos citar a Ordem do Oratório, que implantou na Universidade de Coimbra aspectos iluministas de um catolicismo mais modesto, de um ensino mais adequado à nova ordem implantada. Ainda, na tentativa de ocupar os espaços deixado pelos jesuítas, surgiram algumas escolas que tinham a orientação de religiosos das ordens carmelitas, beneditinos e franciscanos.

Neste âmbito, segundo Teixeira Soares (1961), foi relevante o Alvará de 06 de novembro de 1772:

“[...] que institui o ensino popular a ser dado nas escolas públicas. Pombal não ficou apenas no texto da lei. Passou de imediato à fundação de escolas, que deveriam completar um total de 479. A lei determinou que o ensino popular poderia também ficar a cargo de particulares, que para tanto contariam com apoio do Estado no prelecionamento das seguintes matérias: ortografia, gramática, aritmética, doutrina cristã e educação social e cívica ("civilidade"). O ensino secundário daria ênfase especial ao latim, grego e francês. Ao mesmo tempo que cuidava do ensino popular, fundou o "Colégio dos Nobres", seminário dedicado à educação de filhos da nobreza; e, para manter o equilíbrio social e educacional, fundou também o Colégio de Mafra, destinado à educação dos plebeus, com programa idêntico ao reservado aos filhos da nobreza. [...] O primeiro-ministro criou um imposto especial destinado à manutenção e ampliação das escolas fundadas (lei de 10 de novembro de 1772)". (p. 218).

O que pretendia promover o Ministro Marquês de Pombal foi a substituição dos tradicionais métodos pedagógicos instituídos pela Companhia de Jesus, por uma nova metodologia educacional, condizente com sua realidade e o momento histórico vivenciado. Ou seja, pretendia que as escolas portuguesas tivessem condições de acompanhar as transformações que estavam ocorrendo no século. Neste processo, abriu caminho para novas formas de exclusão.

O desmantelamento da organização educacional jesuítica e a falta de implantação de um projeto educacional foi desastrada e provocou sérias implicações para o ensino no Brasil, destruindo o único sistema de ensino existente no país. (Azevedo, 1976; Niskier, 2001; Ghiraldelli Junior, 2009; Maciel \& Shigunov Neto, 2006 e Shigunov Neto, 2015).

Almeida (2000), apesar de reconhecer a obra do Marquês de Pombal com relação à instrução pública, não deixa de mencionar que após a expulsão da Companhia de Jesus do Brasil e da destruição de sua obra educacional, outras ordens religiosas tentaram continuar a obra iniciada pelos padres jesuítas, contudo, sem grande êxito. Ainda segundo o autor, o êxito do projeto educacional jesuítico deve-se em parte, às grandes habilidades dos padres ao desempenharem a função de professores.

Em relação ao projeto pedagógico pombalino, entre as propostas que o compunham estavam:

- a secularização do ensino;

- a valorização da língua portuguesa;

- o papel e a importância do estudo do latim que seria realizado por intermédio da língua portuguesa. Assim, uma das razões do estudo do latim era a possibilidade de simplificar e abreviar a duração dos estudos;

- a redução do número de anos destinados aos estudos nos níveis de ensino inferiores destinava-se, fundamentalmente, a aumentar o número de ingressos nos cursos superiores;

- a apresentação de um plano de estudos para todos os níveis de ensino, do fundamental (que inicia-se a partir dos sete anos de idade) até os níveis superiores de ensino;

- a ampla presença de disciplinas literárias, tais como: português, latim, retórica, poética e filosofia (lógica, moral, ética, metafísica e teologia), direito (direito civil e direito canônico), medicina (anatomia), grego, hebreu, francês, italiano, anatomia, física (aritmética e geometria);

- a proposição da escola pública e gratuita para toda a população portuguesa, como medida de reduzir o analfabetismo da sociedade. Assim, reivindicava a abertura de escolas públicas em todos os bairros para que ninguém ficasse sem frequentá-las; 
- a recomendação de uma transformação de comportamento dos professores em relação aos seus alunos, visando melhorar a relação professor/aluno;

- a proposição de que a Universidade deveria ser aberta à comunidade e de que membros da comunidade, mesmo sem serem do meio acadêmico, poderiam assistir as aulas ministradas;

- a sugestão de que fossem criados colégios para pobres, a fim de capacitá-los com hábitos do mundo burguês e da nobreza;

- a apresentação de considerações sobre a educação das mulheres, sugerindo a necessidade de que elas frequentassem as escolas para adquirir conhecimentos associados à administração do lar.

Tanto Carvalho (1978), como Avellar (1983) e Ribeiro (1998), concordam que a reforma pombalina sob a égide de seus principais inspiradores, Luís Antonio Verney e Ribeiro Sanches, denominadas de obras modernas, também encontram traços do ensino tradicional - eclesiástico. Portanto, não houve uma ruptura total com o ensino jesuítico, pois a mudança ocorrida foi mais de conteúdo do que de método educacional.

Luís Antonio de Verney (1713-1792) considerado o mais importante difusor do espírito Iluminista da cultura portuguesa, ficou conhecido por sua obra intitulada " $\mathrm{O}$ verdadeiro método de estudar", obra que pretendia opor-se ao método pedagógico dos jesuítas. A obra, que na realidade eram dezesseis cartas escritas por Verney em Roma e publicadas em 1746/1747, apresenta uma análise sobre os defeitos e as consequências desastrosas do ensino português e fornece orientações de como proceder para adequá-los e torná-los condizentes com a nova realidade. Já António Nunes Ribeiro Sanches (1699-1782) formou-se em medicina e foi escritor, sua obra mais famosa foi "Cartas sobre a educação da mocidade".

Segundo Ribeiro (1998), as Reformas Pombalinas pretendiam transformar Portugal numa nação capitalista e, provocar mudanças também no Brasil colônia para atender aos interesses de Portugal. Já em relação a nova orientação do ensino é considerada um retrocesso se vista sob o prisma pedagógico, visto que muito pouco acrescentou ao que já existia na colônia brasileira, e não houve uma ruptura completa com o ensino tradicional.

\subsection{Considerações finais}

Em acordo aos princípios da Filosofia das Luzes (Iluminismo), movimento que impregnou parte da Europa nas décadas finais do século XVII e século XVIII, o Marquês de Pombal implementou uma reforma educacional, justificada pela égide da Ciência e da razão, em oposição ao poder absoluto da igreja, buscando a substituição do ensino eclesiástico pela educação laicizada e pública.

A rigor, as medidas emergenciais adotadas pelas autoridades portuguesas objetivavam alavancar Portugal não apenas por meio de uma nova orientação cultural e educacional, de acordo com o que foi veiculado em todo o Império, mas principalmente pela superexploração colonial.

No contexto brasileiro, na mesma orientação de Azevedo (1976), Niskier (2001) e Maciel \& Shigunov Neto (2006), indicamos que a reforma pombalina foi um retrocesso para a educação, destruindo uma organização educacional já consolidada sem implementar um novo modelo que pudesse substitui-la. Ainda que possam ser questionados os resultados e os fundamentos que guiavam a educação jesuítica, parece-nos pouco conveniente a ideia de destruir uma proposta educacional em favor de outra, sem ter condições para realizar sua consolidação, a exemplo da dificuldade na implementação de escolas como proposto por Pombal, o que ocorreu apenas após quase duas décadas.

Consideramos que essa visão de destruição do existente a partir da intenção de substituí-lo por algo que ainda será elaborado ainda está muito arraigada na política educacional brasileira.

\section{Referencias}

Almeida, J. R. P. de. (2000). Instrução pública no Brasil (1500-1889): história e legislação. História do Ensino de Linguas no Brasil - HELB, s/v, s/p. 
Andrade, A. A. de (Org.). (1965). Luís António Verney: o verdadeiro método de estudar. Lisboa: Editorial Verbo.

Avellar, H. de A. (1983). História administrativa do Brasil: a administração pombalina. Brasillia: FUNCEP/Editora da Universidade de Brasília.

Azevedo, F. de. (1976). A transmissão da cultura: parte 3. São Paulo: Melhoramentos/INL. (5.ed da obra "A cultura brasileira").

Carvalho, L. R. de. (1978). As reformas pombalinas da instrução pública. São Paulo: Saraiva/Editora da Universidade de São Paulo.

Cunha, L. A. (1986). A universidade temporã. Rio de Janeiro: Francisco Alves.

Falcon, F. J. C. (1993). A época pombalina: Politica econômica e monarquia ilustrada. São Paulo: Ática.

Ghiraldelli Junior, P. (2009). História da educação brasileira. 4.ed. São Paulo, Cortez.

Haidar, M. de L. M. (1973). A instrução popular no Brasil antes da República. In: M. Brejon (Org.). Estrutura e funcionamento do ensino de $1^{\circ}$ e $2^{\circ}$ graus (pp. 37-51). São Paulo: Pioneira.

Holanda, S. B. de. (1989). História geral da civilização brasileira: a época colonial. v. 1, 8.ed. Rio de Janeiro: Bertrand Brasil. Brasil.

(1993). História geral da civilização brasileira: o Brasil monárquico. v. 1. Rio de Janeiro: Bertrand

Maciel, L. S. B. \& Shigunov Neto, A. (2006). A educação brasileira no período pombalino: uma análise histórica das reformas pombalinas do ensino. Educação e Pesquisa, 32, pp. 465476. http://www.scielo.br/scielo.php?script=sci_arttext\&pid=S151797022006000300003\&lng=en\&nrm=iso. Acesso em 30 de Março de 2018.

Monroe, P. (1978). História da educacaão. 13.ed. São Paulo: Editora Nacional.

Niskier, A. (2001). Educação Brasileira: 500 anos de História. Rio de Janeiro: FUNARTE.

Rêgo, R. (1984). As comemorações pombalinas. In: M. H. C. dos Santos (Org.). Pombal revisitado. (pp. 15-18). Lisboa: Editorial Estampa.

RÊGO, Raul (1982). "As comemorações pombalinas". In: Maria Helena Carvalho dos Santos (org.). Pombal revisitado. Vol. I. Lisboa: Estampa, pp. 15-18.

Ribeiro, M. L. S. (1998). História da educação brasileira: a organizaçãao escolar. 15.ed. Campinas: Autores Associados.

Romanelli, O. de O. (1993). História da Educação no Brasil. 15 ed. Petrópolis: Vozes.

Santos, M. H. C. dos. (1982). Poder, intelectuais e contra-poder. In: M. H. C. dos Santos (Org.). Pombal revisitado (pp. 122-129). Lisboa: Editorial Estampa.

Saviani, D. (2013). História das ideias pedagógicas no Brasil. 4.ed. Campinas: Autores Associados.

Serrão, J. V. (1982). História de Portugal: o despotismo iluminado (1750-1807). v. 6, Lisboa: Editorial Verbo.

Shigunov Neto, A. (2015). História da educação brasileira: do período colonial ao predominio das políticas educacionais neoliberais. São Paulo: Salta.

Teixeira Soares, Á. (1961). O Marquês de Pombal. Brasilia: Editora da Universidade de Brasília. 